\title{
Social Cognitive Intervention: Improving Coping Ability of Rural Adolescents with Educational Stress
}

\author{
T. Manirathinam ${ }^{1}$, A. Velayudhan ${ }^{2}$, Palanisamy V. $^{3}$ \\ ${ }^{1}$ Research Scholar, Department of Psychology, Bharathiar University, Coimbatore-46, ${ }^{2}$ PI, UGC-MRP, Professor \\ and Head, Department of Psychology, Bharathiar University, Coimbatore-46, ${ }^{3}$ Assistant Professor, Indian Institute \\ of Psychology and Research, Bangalore-95
}

\begin{abstract}
Educational Stress affects the both students' mental health and physical health. Mounting demand of the society, and various academic requirements make some students to perceive education as stressful task. Particularly conditions of the students from the rural area are most vulnerable as they getlack of guidance and academic related support from their family. Students usually perceive high educational stress when they think that academic demands are unattainable or above their capacity. Objective of the current study is to find out the efficacy of social cognitive intervention in improving the coping ability of rural adolescent students with the educational stress. 100 students were selected as a sample from the rural area of Coimbatore district, Tamil Nadu by using purposive sampling method. Single group pre-test, post-test and follow up research design were used. Statistics used include mean, SD, repeated measure ANOVA and post-hoc were used to analyze the data. Results showed that rural adolescent students had gained their coping ability in educational stress after the social cognitive intervention.
\end{abstract}

Keywords: Educational Stress, rural adolescents, and social cognitive intervention.

\section{Introduction}

In India students from the rural area are still struggling to launch themselves into the mainstream of the society. Rural students are in the disadvantaged condition in terms of educational achievement, and career development. Transforming students from the underprivileged background to rapidly growing modern society is a challenging task. School is the crucial place for the rural students in which they can learn and acquire knowledge. The school education and education related activities may be strange or incompatible for many rural students. High expectation from the parents and examination related necessities are the major stressors among the rural students. Students are needed to meet various academic demands such as writing assignment, preparing for class tests and examination within the limited time period or simultaneously. As a result of their troubled adaptation toward school, they experience educational stress. Educational stress causes numerous problems include poor academic performance, mental health problems and physical problems. Often academic related stress become as a chronic stress. ${ }^{1}$ Educational stress affects the academic achievement of the students. ${ }^{2}$
Stress and Education: Academic learning is an important source of stress among students and it is high in the Asian countries ${ }^{3}$. As students experiencing educational related stress they will lose hope in their higher education that they wish to pursue. They determine themselves as unfit for the education and that they restrict themselves with the rural based jobs. Educational stress leads to a huge number of drop out of students from school happening in rural areas, therefore it is not a problem of student community alone but it has repercussions on the entiresociety. Students' suicide is high in India particularly in Tamil Nadu this issue draws the wide attention since number of cases are high and which is related to the examination and grade. Rural adolescents are at the risk of developing depression and suicidal ideation due to the educational stress. Students with educational stress are likely to develop suicidal ideation ${ }^{4}$. Students from the rural areas may have skills and ability but their lack of stress coping ability affects their performance. Those who experienced educational stress have low achievement motivation ${ }^{5}$. We should have a clear policy in finding out to assist students, and then it would help many students to enter into right 
career path. If bright and skillful students were restricted themselves in simple village based jobs, then the society will be suffer with inadequate human resource for many professions. This problem of rural adolescents' would affect the human resource developmentof India.

Perceived outcome of examination is the important predictor of the educational stress among the students ${ }^{6}$. Education related stress affects Students' interest and perseverance ${ }^{7}$. The high academic expectation of parents leads to the maladaptive behavior of the students ${ }^{8}$. Health and wellbeing of the students are the predictors of the academic success ${ }^{9}$. Emond ${ }^{10}$ conducted a study to find out the effect of academic stress on adolescent students eating behavior. The results of the study revealed that high academic stress is related to the overeating behaviour. Brain regions including ventromedial prefrontal cortex and amygdala which is responsible to induce the eating desire is active during the experience of academic stress. Subsequently student with educational stress prefers to eat high calorie food ${ }^{11}$. Students experiencing examination related stress are highly anticipated to the upcoming events ${ }^{12}$.

\section{Social Cognitive Intervention}

Social cognitive intervention was developed based on Bandura's Social cognitive theory and Vygotsky's social developmental theory. Bandura ${ }^{13}$ proposed the model called reciprocal determinism. In this model behavior, cognition and other personal factors, and environmental influences all operate as interacting determinants that influence each other bidirectionally. $\mathrm{He}$ also argued that each elements of reciprocal determinism does not influence behavior equally, some may be stronger than others. During the early years of life, changes occur rapidly. People process and transform passing experiences by means of verbal, imagination and other symbols into cognitive models of reality that serve as guides for judgment and action. Guided instruction from others, verbal reinforcement and observing others behavior effectively influence cognitive development of the children. Self modeling video is the effective technique to enhance the behavior and academic participation of the school students. Modeling behavior is useful for the basic life skills of adolescents with developmental disorder. Schlichting revealed that selfmodeling video intervention significantly reduced the public speaking anxiety of school students.

\section{Method}

Objective of the Study: Find out the efficacy of social cognitive intervention on improving the coping ability with educational stress of rural adolescent.

\section{Hypotheses:}

1. Rural adolescents' pressure from study will be reduced after the social cognitive intervention

2. Rural adolescents' Work Load will be reduced after the social cognitive intervention

3. Rural adolescents' Worry about Grades will be reduced after the social cognitive intervention

4. Rural adolescents' Self-expectation will be reduced after the social cognitive intervention

5. Rural adolescents' Despondency will be reduced after the social cognitive intervention

Sample: 100 rural students studying $11^{\text {th }}$ grade were selected from the Government Higher Secondary School located in rural area of Coimbatore district in Tamil Nadu, sample included 50 male and 50 female participants from underprivileged category. The purposive sampling method was used to select the sample. Inclusion criteria for selecting samples are first generation school students and students from Scheduled Caste (SC) Scheduled Tribe (ST) and Other Backward Class (OBC). Exclusion criteria of students those whose parents were educated and Students who were already had exposure with similar training program.

Intervention: Social cognitive intervention was developed in order to facilitate the rural students to get exposure with new environment where they can observe, imitate, and discuss the different skills and behavior. During the intervention four method were used as primary techniques namely modeling, roleplay, reinforcement, and feedback. Modeling videos were shown with the theme of coping with educational stress. Stories of great individuals those who have overcome their stressful situation and achieved success in their life were discussed. During the role play session participants performed the play with the theme of coping with educational stress. Facilitator gave feedback to the role play performance in order to indicate the merits and demerits of the strategy which was used by the performers to cope with educational stress. Participants those who performed most suitably in the role play were reinforced by the facilitator. Socially guided learning will 
encourage children to act self-directionally for dealing intelligently with difficult situations in future. Vygotsky argued that in the classroom, teachers have to provide space for peer instruction, collaboration, and small group interaction. Vygotsky believes that development is a lifelong process and social interaction is the major factor which predicts the individual's cognitive development.

Tools:

- Educational stress Scale for Adolescents ${ }^{14}$
Research Design: Single group Pre-test, Post-test, and follow up experimental method was used to identify the effectiveness of the social cognitive intervention.

Statistics: Mean, SD, ANOVA, Post hoc tests were used to analyze the data. SPSS 16 software was used to process the data.

\section{Results and Discussion}

The data collected analyzed and the results are discussed accordingly.

Table 1 Mean and SD of Educational Stress in Pre-test, Post-test and follow-up among the Rural Adolescents

\begin{tabular}{|l|c|c|c|c|c|c|c|}
\hline \multirow{2}{*}{} & \multirow{2}{*}{ N } & \multicolumn{2}{|c|}{ Pre-test } & \multicolumn{2}{c|}{ Post-test } & \multicolumn{2}{c|}{ Follow Up } \\
\cline { 3 - 8 } & & Mean & SD & Mean & SD & Mean & SD \\
\hline Pressure fromS tudy & 100 & 4.43 & .671 & 2.30 & 1.124 & 1.69 & .647 \\
\hline Work Load & 100 & 4.46 & .626 & 2.16 & .662 & 1.54 & .626 \\
\hline Worry about Grades & 100 & 4.57 & .671 & 2.22 & .799 & 1.69 & .692 \\
\hline Self-expectation & 100 & 4.57 & .655 & 2.21 & 1.047 & 1.62 & .616 \\
\hline Despondency & 100 & 4.26 & .872 & 2.21 & 1.047 & 2.12 & 1.018 \\
\hline
\end{tabular}

Table 1 shows the mean differences of the participant's academic pressure in pre-test, post-test and follow up in order to find out whether the skill-streaming intervention has made any impact on academic stress.

Pressure from study was $\bar{X}=4.23$ during the pre-test, after the intervention it got reduced with the mean value of 2.30 in the post-test. Follow up test was conducted after the three months gap from the time of intervention and there was a reduction in the mean value $(\bar{X}=1.69)$. Work load which is perceived by the participants during the pre-test was $\bar{X}=4.46$ after the intervention they perceived it less $(\bar{X}=2.16)$. Similarly they perceived less work load during the follow up $(\bar{X}=1.54)$. Participants worry about grade was very high during pre-test with the mean score of 4.57 and their level of worry about grade was low in the post-test $(\bar{X}=2.22)$. Their level of worry about grade reduced further during follow up test after the three months which revealed the mean score 1.69 and it is very less when compared to the mean scores of pre-test and post-test.

Table 1 shows that self-expectation of the students in the pre-test was $\bar{X}=4.57$ which was very high. The troubled self-expectation has been reduced after the intervention with the mean score of $\bar{X}=2.21$ and again in the follow up test self-expectation got highly reduced with mean score of 1.62. Likewise despondency of the student was very high in pre-test $(\bar{X}=4.26)$ and in posttest there were a reduction $(\bar{X}=2.21)$ in it. Follow up test shows that students' level of despondency decreases $(\bar{X}$ $=2.12$ ) however there was no notable difference between the mean of post-test and follow up.

Table 2: F Values for Pre-test, Post-test and Follow Up in Educational Stress among the Rural Adolescents

\begin{tabular}{|l|l|c|c|c|c|c|}
\hline Source of variation & Variable & Type III Sum of Squares & df & Mean Square & F & Sig. \\
\hline \multirow{5}{*}{$\begin{array}{l}\text { Within group } \\
\text { variance }\end{array}$} & Pressure From Study & 413.887 & 1.802 & 229.625 & 308.592 & .000 \\
\cline { 2 - 7 } & Work Load & 473.360 & 1.925 & 245.879 & 611.465 & .000 \\
\cline { 2 - 7 } & Worry about Grades & 469.927 & 1.993 & 235.842 & 438.590 & .000 \\
\cline { 2 - 7 } & Self-expectation & 483.860 & 1.979 & 244.481 & 523.673 & .000 \\
\cline { 2 - 7 } & Despondency & 293.007 & 1.972 & 148.609 & 146.755 & .000 \\
\hline
\end{tabular}




\begin{tabular}{|l|l|c|c|c|c|c|}
\hline Source of variation & Variable & Type III Sum of Squares & df & Mean Square & F & Sig. \\
\hline \multirow{5}{*}{ Error } & Pressure From Study & 132.780 & 178.442 & .744 & \\
\cline { 2 - 7 } & Work Load & 76.640 & 190.592 & .402 & \\
\cline { 2 - 7 } & Worry about Grades & 106.073 & 197.262 & .538 & & \\
\cline { 2 - 7 } & Self-expectation & 91.473 & 195.934 & .467 & \\
\cline { 2 - 7 } & Despondency & 197.660 & 195.195 & 1.013 & & \\
\hline
\end{tabular}

Table 2 shows the results of ANOVA that there is a significant difference between the pre-test, post-test, and follow-up phases of academic stress that includes Pressure From Study, Work Load, Worry about Grades,
Self-expectation, and Despondency. Further the post hoc comparison presented below gives a clear picture as to the significant differences that happened during the three phases of the study.

Table 3 Post-Hoc test for Pre-test, Post-test and Follow up Phases in Educational Stress among the Rural Adolescents

\begin{tabular}{|c|c|c|c|c|}
\hline & Phase(I) & Phase(J) & MD & Sig \\
\hline \multirow{3}{*}{ Pressure From Study } & \multirow{2}{*}{ Pre-test } & Post-test & 2.13 & * \\
\hline & & Follow-up & 2.74 & $*$ \\
\hline & Post-test & Follow-up & .61 & $*$ \\
\hline \multirow{3}{*}{ Work Load } & \multirow{2}{*}{ Pre-test } & Post-test & 2.30 & $*$ \\
\hline & & Follow-up & 2.92 & $*$ \\
\hline & Post-test & Follow-up & .6 & $*$ \\
\hline \multirow{3}{*}{ Worry about Grades } & \multirow{2}{*}{ Pre-test } & Post-test & 2.35 & $*$ \\
\hline & & Follow-up & 2.88 & * \\
\hline & Post-test & Follow-up & .53 & $*$ \\
\hline \multirow{3}{*}{ Self-expectation } & \multirow{2}{*}{ Pre-test } & Post-test & 2.33 & $*$ \\
\hline & & Follow-up & 2.95 & $*$ \\
\hline & Post-test & Follow-up & .62 & $*$ \\
\hline \multirow{3}{*}{ Despondency } & \multirow{2}{*}{ Pre-test } & Post-test & 2.05 & $*$ \\
\hline & & Follow-up & 2.14 & $*$ \\
\hline & Post-test & Follow-up & .09 & NS \\
\hline
\end{tabular}

*Significant at 0.05 level

Table 3 shows the difference of pre-test, post-test and follow up with each other. Difference between the pre-test and post test of pressure from study was found to be significant $(\mathrm{MD}=2.13, \mathrm{p}=.000)$. Significant difference was also found between the pre-test and follow up phase $(\mathrm{MD}=2.74, \mathrm{p}=.000)$. Likewise difference between the post-test and follow up phase was also found significant $(\mathrm{MD}=.61, \mathrm{p}=.000)$. Generally most of the adolescents were facing severe pressure as a result of mounting academic demands. From the students point of view many things are putting pressure on to them such as continuous class, time shortage, less time for sport and relaxation. After the social cognitive intervention they have perceived very less pressure. Techniques related to handling pressure have helped them to cope with academic pressure.

Difference between the pre-test and post-test was found to be significant ( $\mathrm{MD}=2.30, \mathrm{p}=.000)$ in the work load dimension of the educational stress. Similarly difference of the pre-test and follow up phase was found to be significant $(\mathrm{MD}=2.92, \mathrm{p}=.000)$. Difference in the 
post-test and follow up phase were also found to be significant $(\mathrm{MD}=.62, \mathrm{p}=.000)$. Reading different subjects' books, doing assignments for all the subjects, completing syllabus before examination have become over load to the students. Adolescents those who participated in this study have been scoring high on work load in the pretest phase. After the social cognitive intervention their attitude toward work load have changed therefore their score was very less in the post-test and follow up.

Worry about grades got significantly reduced from pre-test to post-test phase ( $\mathrm{MD}=2.35, \mathrm{p}=.000)$. Similarly a comparison between the pre-test and follow up test phase revealed a significant $(\mathrm{MD}=2.88, \mathrm{p}=.000)$ difference between these two tests. Likewise the posttest and follow up of worry about grades are significantly different $(\mathrm{MD}=.53, \mathrm{p}=.000)$. Very high expectation from family, school and society toward a student make his/her thinking highly concerned about their grade or marks in the school. Particularly in India grades are considered as sole predictor of students' ability by the society. Therefore if there is any lacking in the grade then he/ she will be labeled by the society as an 'unfit' person for successful career. This scenario will increase the worry of the students. In Tamil Nadu, students' suicide is frequently occurring incident because of low marks in public examinations. In the state a student committed suicide even before the results were announced, it costs his life just because of fearing of low marks in upcoming $12^{\text {th }}$ standard results ${ }^{15}$. Brown, Johnson, and McPherson ${ }^{6}$ revealed that examination is the major cause for the academic stress of the students. Social cognitive intervention has reduced the students' worry about grade. Modeling and role play was performed with the theme of changing attitude toward grades followed by feedback from the facilitator which consisted with Logo therapy techniques including changing attitude toward conditions.

In the self-expectation dimension of the educational stress was found to be significant ( $\mathrm{MD}=2.33, \mathrm{p}=.000$ ) when pre-test and post-test was compared. Likewise significant difference was found between the pre-test and follow up phase $(\mathrm{MD}=2.95, \mathrm{p}=.000)$. Difference between the post-test and follow up was also found to be significant $(\mathrm{MD}=.62, \mathrm{p}=.000)$. According to Rogers (1961) individuals those who are façade themselves in order to be an ideal person for others while failing to understand his/her own uniqueness will face mental health problems. Social cognitive intervention helped adolescents to improve their internal communication.
They can understand their own uniqueness and potential, once their internal communication improves.

Students' Despondency was found to be significantly different $(\mathrm{MD}=2.05, \mathrm{p}=.000)$ while comparing the pretest and the post-test. Difference was also found between the pre-test and follow up ( $\mathrm{MD}=2.14, \mathrm{p}=.000)$. There was no significant difference $(\mathrm{MD}=.09, \mathrm{p}=\mathrm{NS}$ ) found between the post-test and follow up.

Since these students have uneducated or under educated parents that affect their relation with institutes. Students those who had parents without college education experience more stress than their counterpart those who have parents with college level education ${ }^{16}$.

Internal communication improvement strategies and self-focused techniques were practiced by the participants during the examination in order to cope up with their despondency. Self-focused techniques will help to reduce the despondency of the students ${ }^{17}$. Overall stress of the students was reduced significantly after the social cognitive intervention.

Stress is a major mental health problem of the adolescents and it affects the academic performance and leads to long term mental health problems. The risk of educational stress is that it is one of the major predictors of chronic stress ${ }^{1}$. Academic stress is highly related to the eating related problems ${ }^{11}$. Cortical anticipatory activities are high among students with examination induced academic stress ${ }^{12}$. Final exam stress is vulnerable to the students with asthma related problems ${ }^{18}$. Academic stress is highly related to the internet addiction and negative emotions ${ }^{19}$. Academic stress affects the students' intrinsic motivation and improves the motivation ${ }^{20}$. Students with skin picking behavior reportedly are affected by the Education related stress $^{21}$. Stress will inhibit the students from showing his/ her ability on education and also stress will be a cause for dropping out from the school ${ }^{22}$. Numerous researches have showed that education stress is a significant problem faced by the adolescent students. Particularly the cases of students from the rural area who are struggling to cope up with the stress are mostly related to their education. Lot of education related stress produces the short-term and long-term problems for the students. Therefore the educational stress should be reduced by providing necessary techniques to the students. Results of the present study showed that social cognitive intervention significantly reduced the educational 
related stress among the rural students. During the intervention students participated in intervention related actives including modeling, role-play, reinforcement and feedback with the theme of stress reduction and the results have proved that participants' educational stress was significantly reduced. If the rural adolescents learnt to cope with the stress that they are facing in strange places and culture differences in school then they can meet the academic requirements like other students. Stress reduction programs are important to improve the academic performance of the high school students ${ }^{23}$.

\section{Conclusions}

Results supports that social cognitive intervention was effective technique in reducing the educational stress of the rural adolescents. Before the intervention students' level of pressure from study, work load, worry about grades, self-expectation, and despondency was high. After the intervention they perceived very less in all the dimensions of the educational stress. As students acquired skills to cope up with educational stress they have perceived less educational stress after the intervention. Their coping ability with educational stress will help students to develop their mental health, and academic performance.

\section{Implications:}

- Social cognitive intervention can be implemented in the government schools were rural students are studying.

- Those Students who are preparing for public examination may undergo social cognitive intervention to tackle examination related stress.

- School psychologist can use the social cognitive intervention to students who are affected by the educational stress.

- Government and non-governmental organizations working in suicide prevention program may use the social cognitive intervention.

Ethical Clearance: Taken from Doctoral committee constituted by the University

Source of Funding: Self

Conflict of Interest: Nil

\section{References}

1. Radillo, B.E.P., Serrano, M.L.P., Fernández, M.A.,
Velasco, M.A.A., \& García, D.D.D. Academic stress as a predictor of chronic stress in university students. Psicología Educativa.(2014); 20 :47-52.

2. Elias, H., Ping, W.S., \& Abdullah, M.C. Stress and Academic Achievement among Undergraduate Students in Universiti Putra Malaysia. Social and Behavioral Sciences.(2011); 29 : 646 - 655.

3. Brown, S. L., Teufel, J. A., Birch, D. A., \& Kancherla, V. Gender, age, and behavior. Differences in early adolescent worry. Journal of School Health. (2006);76:430-437. doi:10.1111/ j.1746-1561.2006.00137.x.

4. Deb, S., et al. Depression among Indian university students and its association with perceived university academic environment, living arrangements and personal issues. Asian Journal of Psychiatry. (2016); 23 : 108-117.

5. Karaman, M.A., \& Watson, J.C. Examining associations among achievement motivation, locus of control, academic stress, and life satisfaction: A comparison of U.S. and international undergraduate students. Personality and Individual Differences. (2017); 111 : 106-110.

6. Brown, K., Johnson, P.A., \& McPherson, A.N. Academic-related stress among graduate students in nursing in a Jamaican school of nursing. Nurse Education in Practice. (2016); 20 : 117-124.

7. Lee, W. Relationships among grit, academic performance, perceived academic failure, and stress in associate degree students. Journal of Adolescence. (2017); 60 : 148-152.

8. Chong, W.H., Chye, S., Huan, V.S., \& Ang, R.P. Generalized problematic Internet use and regulation of social emotional competence: The mediating role of maladaptive cognitions arising from academic expectation stress on adolescents. Computers in Human Behavior. (2014); 38 : 151-158.

9. Glozah, F.N., \& Pevalin, D.J. Social support, stress, health, and academic success in Ghanaian adolescents: A path analysis. Journal of Adolescence. (2014); 37 : 451-460.

10. Emond, M., et al. The effect of academic stress and attachment stress on stress-eaters and stressundereaters. Appetite. (2016); $100: 210-215$.

11. Neseliler, S., et al. Academic stress and personality interact to increase the neural response to highcalorie food cues. Appetite. (2017); 116 : 306-314.

12. Hongxia, D., et al. Anticipatory processes under 
academic stress: An ERP study. Brain and Cognition. (2015); 94 : 60-67.

13. Bandura, A. Social foundations of thought and action: A social cognitive theory. Englewood Cliffs, NJ: Prentice-Hall. (1986).

14. Sun, J., Dunne, M. P., Hou, Xiang-Yu, \& Xu, A. Educational stress scale for adolescents : development, validity, and reliability with Chinese students. Journal of Psychoeducational Assessment. (2011); 29 : 534-546.

15. Asia News International. Tamil Nadu: Student Commits Suicide fearing failure in Class 12th Exam. NewsX. (2016, May 18); p. 1.

16. Morazes, J. Educational background, high school stress, and academic success. Children and Youth Services Review. (2016); 69 : 201-209.

17. Rawal, A., Williams, J.M.G., Park, R.J. Effects of analytical and experiential self-focus on stressinduced cognitive reactivity in eating disorder psychopathology. Behaviour Research and Therapy. (2011); $49:$ 635-645.

18. Trueba,A., Ryan, M.W., Vogel,P.D., Ritz, T. Effects of academic exam stress on nasal leukotriene B4 and vascularendothelial vascularendothelial growth factor in asthma and health. Biological Psychology. (2016); $118: 44-51$.

19. Jun, S., \& Choi, E. Academic stress and Internet addiction from general strain theory framework. Computers in Human Behavior. (2015); 49 : 282 287.

20. Liu, Y. The longitudinal relationship between Chinese high school students' academic stress and academic motivation. Learning and Individual Differences. (2015); $38:$ 123-126.

21. Yeo, S.K., \& Lee, W.K. The relationship between adolescents' academic stress, impulsivity, anxiety, and skin picking behavior. Asian Journal of Psychiatry. (2017);28 : 111-114.

22. Misra, R. \& Castillo, L. Academic Stress among College Students: Comparison of American and International Students. International Journal of Stress Management. (2004); 11 : 132-148.

23. MoghimIslam, M., Jafari, P., \& Hoseini,M. Impact of stress management training on the girl high school student academic achievement. Social and Behavioral Sciences. (2013);89: $22-26$. 